\section{EPIDEMIOLOGY IN DEVON*}

\section{BY}

\section{R. M. S. McCONAGHEY, M.D. General Practitioner, Dartmouth}

The study of epidemic disease is one of the most fascinating branches of medicine which we in general practice encounter. To unravel an outbreak of infection, from whatever cause, requires the detective powers of a Sherlock Holmes, the patience of a dermatologist, and the deductive reasoning of a skilful lawyer. Devon has been blessed with more than its share of epidemiologists. It has also, perhaps, been cursed with more than its share of epidemics.

Broadly, we may divide the epidemiology of the country into five ages, according to the impact which certain diseases had upon life in each period. Thus we cannot think of life in the early Middle Ages without associating it with leprosy. The age of plague extended from the Black Death in 1348 to the Great Plague of London in 1665, when it died out as suddenly as it had arrived, over 300 years before. Its place as Captain of the Men of Death was almost immediately taken by smallpox. The age of smallpox extended until the first quarter of the nineteenth century, when it began to fade away under the gathering attack of the disciples of Jenner. No sooner was it under control than a fresh invader-Asiatic cholera-took its place. Filthy overcrowded hovels and a complete lack of sanitation fostered not only cholera but also the enteric fevers, which flourished until the work of Chadwick and Simon, Snow and Budd, began to clear up the slums in which they were endemic. So we come to our own times: we live too near to say what fell disease will be singled out as our chief destroyer.

\section{The Age of Leprosy}

Let us take each age and see how it has made its mark in our history. I will not linger over leprosy. The remains of leper hospitals may be seen here and there in our towns and villages, and place names-Magdalene Street in Exeter and Maudlin Road in Totnes-mark the sites of them ; lazar houses were usually built on the outskirts of towns, and the fact that so many streets with these names are now near the centre of the boroughs gives us some idea of the growth of our municipalities since the Middle Ages.

\section{The Age of Plague}

The Black Death, when it came, left so great a devastation in its trail that there were no opportunities at the time for recording its ravages. Exeter, Winchester, and Norwich were the worst-hit dioceses in the country, and the deanery of Kenn, around Haldon Hill, was the worst-hit deanery of all England, losing 86 incumbents from its seventeen churches in the years 1348-51. The mortality was not confined to the towns or even villages; in the parish of Templeton, where there is no village, the dead were collected by the cartload from the scattered farmsteads and taken by night to the mother church of Witherbridge for burial. The bailiff's account for Dartmoor Manor in 1350-1 gives a long list of the moorland farms " in the hands of the Lord for the want of tenants." The effect on the tin-miners was disastrous. Ashburton, a stannary town which had also developed a flourishing cloth market, declined in importance for a long time after.

Plague epidemic years in London were 1583, 1592-4, $1602,1625,1630,1636$, and 1665 . In Devon the epidemic

*Presidential Address (abridged) delivered to the South-western Branch of the British Medical Association on June 1, 1957. waves did not necessarily follow the same pattern. In 1579 it is said that 600 people died in Plymouth. In 1690 and 1691 it was again at Plymouth. In the Totnes parish register is entered "the first of the plague, Margory, the daughter of Mr. Wyke of Dartmouth, June 22, 1590," which leads one to suppose that the disease had spread in the person of Margory, from that town, though of this I have no records. In Totnes 246 died in the following seven months: 42 in July and 81 in August.

The plague of 1592-4 was very severe both in London and in the country, and the Privy Council took sound and prompt steps for its control. In 1593 it issued orders " to be executed throughout the counties of this realm, in such towns, villages, and other places as are, or maybe hereafter infected with the plague, for the stay of further increase of the same." These orders called for a general meeting of all the justices (except those residing in or near infected places), in every county, to be held in a place not infected by plague. At this meeting they were to determine in what places the plague was; levy taxes ; instruct the parishes to appoint searchers to view the bodies of all that died, whether the plague was present or not; shut up for six weeks the houses of any who died of the plague; station watchmen to ensure that these regulations were carried out; and appoint honest persons to collect money to provide those shut up with victuals. In every shire-town remedies and preservatives against the plague were to be collected, so that the smaller villages might be supplied in emergency. Clothes and bedding were to be burnt or disinfected and the owners compensated if poor. These orders called for a weekly return from the churchwardens or the ministers or curates of all that died of the plague. The justices of the shire were to meet every 21 days, and those of the hundreds every week. These orders, to which were appended recommendations by physicians on the best remedies, were to be fixed to notice boards in the marketplaces or in the churches.

I have not been able to find any records of meetings of the justices having been held in Devon, but there is ample evidence that the recommendations were complied with In Plymouth, in 1590-1, £5 19s. was paid "towards the charge of such as were kept in for avoiding the sickness"; and in Barnstaple, in 1603-4, 6s. 3d. was paid "for the provision of divers that were willed to keep themselves and their houses in Crocle Street for suspicion that the plague had been amongst them." In 1649 they "paid for the relief of Mr. Witchhole and others shut up on suspicion of the sickness, 9s. 4d." In that year the pestilence was at Ravansleigh, and the town spent $£ 3$ 1s. in order to secure goods and preserve the town from infection.

Not only were suspected cases confined to their houses, but from even earlier times traffic with infected places was suspended. In 1563 Exeter passed a local order to prevent London merchants and packmen coming to the fair of St. Nicholas.

The provision of pest-houses during the later epidemics was common. These were not permanent hospitals but houses commandeered for the purpose; but occasionally they were specially built. During the plague of 1601-2 Plymouth lodged their sick in the "ploemilles." When it struck again in 1624-5 a special house was built in the fields out of the town "wherein the Mayor was chosen being wholly occasioned by means of the plague then in the town," and a pest-house was at the same time erected. In the Tavistock parish records is a "humble petition" dated 1677 which shows how the parishioners went about the establishment of a pest-house. It is addressed to the Earl of Bedford, and sets forth the existence of a "little cottage much ruined with two little garden plotts to the same belonginge, called by the name of St. Johns's Chapple bought by the p'shoners of Tavistock in the time of the late contagious sickness, and then converted to a pest-house and was verie useful and beneficial to your said Town and Borough." This property having fallen into the hands of the Earl, the petitioners asked him to grant a lease for 99 
years on three lives at the ancient rent of $1 \mathrm{~s}$. a year, to be "altogether converted to the use of the poor of your said Towne and Borough, except great necessitie constraine us again to convert it to a Pest House."

\section{The Age of Smallpox}

The sudden disappearance of plague after 1665 left smallpox as the most feared of epidemic diseases. The best account of the disease in the South-west came from the pen of John Huxham, the great physician of Plymouth, who described its occurrence in Plymouth in 1724 in a paper published in the Philosophical Transactions of the Royal Society. Huxham was born in Totnes in 1692, the son of a butcher, and was educated at the school of Isaac Gilly, of Newton Abbot. In 1715 he studied at Leyden under Boerhaave and gained the M.D. of Rheims in 1717. Returning to England, he settled at Totnes, but soon after moved to Plymouth. He must have had unbounded energy, for he achieved an international reputation. In his younger days he is said to have arranged with his servant to call him out of Chapel-he was a Dissenter-whereupon he would drive out of one of the gates of the town and in at another; he must have made a conspicuous figure, for we are told that, though he affected great gravity of manner, his ordinary dress was a scarlet coat with ruffles at the wrist and a cocked hat. He was short in build, fair in complexion, and had a cast in his left eye. Huxham was all his life a prolific writer of notes; these form the basis of his published works.

From our point of view, his most interesting book is his Observations on the Air and Epidemic Disease, published in 1759. This work consists of his records of the weather and the epidemic diseases of Plymouth, month by month during the years 1728 to 1737 . From it we can obtain one of the most complete pictures of the type of disease commonly encountered by a general practitioner in the first half of the eighteenth century. Thus we read that February, 1728, was a dry month: "Coughs are now becoming very epidemical, especially in the younger sort of People, who are affected with great Rheums, Pains of the Teeth and Fauces, with swellings of the parotid and maxilliary glands. ... In this month likewise the SmallPox were up and down the Country, but mild and seldom fatal." In September of that year: "Intermittent fever up and down, and some putrid: Fluxes of the Belly in Abundence, but Colics more seldom than usual at this Seasonnot a few are seized with inflammation of the Eyes, and Tumours of the Neck and Throat." In October there were "Petichial Fevers here and there, and some Erysepelatose"; and in November there was a murrain amongst the cattlecolds, catarrhs, and coughs were very frequent. In December "Rheumatic Fevers up and down, and frequent asthmatic Paroxysms ; abundence of very severe Coughs."

The following year the prevailing distempers were, in January, chilblains; in February, severe fits of gout and rheumatism; in March he says of the gout, "I scarce remember more obstinate Torments in them nor the Gout more anomolous." April was "A baneful season for tabid Persons"; and in June he notes, "Erysepelas and Smallpox epidemic, Slow nervous fevers frequent .... and Headaches and Madness up and down." By July smallpox was prevalent, and in August it became very virulent. In this month the itch infected many persons. In September the smallpox raged very greatly, with purple and often also black spots; and so it continued to the end of the year.

The other condition which interested Huxham was the Devonshire colic. In a small treatise on the outbreak which occurred in 1724 he gave a description of this very local condition. The disease was due to drinking cider, and Huxham was convinced that the cause was the newness and sharpness of the fresh beverage. His description is a good example of his powers of observation and description: "This Disease began its Attack, by an excessively tormenting Pain in the Stomach, and epigastric Region, with an unequal. weak Pulse or coldish sweats; the tongue in the mean Time was coated with a greenish or brown Mucus, and the Breath was most offensive. An enormous Vomiting soon followed, for the most part of exceeding green Bile, sometimes black, with great Quantity of Phlegm excessively acid and tough. ... Things continuing in this state for a day or two, the Belly became extremely bound, neither answering to the most drastic Purges, or the sharpest Clyster, the latter coming off without Wind or Stool, the former being soon vomited.

"The Vomiting abated somewhat, the Pains descended, and most grievously tormented the umbilicus and small of the Back, so that you might have thought the patient actually laboured under a nephritic Paroxysm, and the rather as a suppression of urine now also comes on and yet a perpetual desire to that discharge is urgent." This clinical description is easily recognized as a picture of heavy-metal poisoning, and as such could hardly be bettered to-day. Indeed, it would not be written in such graphic English. We have lost the art of clear, vigorous expression.

The problem of the cause of cider colic was solved by Sir George Baker-another native of the South Hams, who was born in 1722, the son of the Archdeacon and Regrator of Totnes and Vicar of Modbury, and educated at Eton and King's College, Cambridge. Baker was universally acknowledged as one of the most learned physicians of the century. "No Man," said Monk, "ever followed the career of physic and the elegant paths of the Greek and Roman muses with more success"; and a nearer contemporary, Macmichael, wrote in The Gold-Headed Cane: "To him the whole medical world looked up with respect, and in the treatment of any disease in the least unusual, if it was desired to know all that had ever been said or written on the subject, from the most remote antiquity, down to the case in question, a consultation was proposed with $\mathrm{Sir}$ George Baker. From his erudition everything was expected."

Baker's "Essay Concerning the Cause of the Endemical Colic of Devonshire" bears out the eulogies of these men, and is worthy of study as one of the earliest attempts to combine epidemiological and clinical observation with chemical analysis. His account opens with a few words on the duty of physicians to prevent diseases. "A malady, so formidable as well in its immediate effects, as in its more distant consequences, it is an office of humanity, as much as possible to prevent." These words, coming at a time when most medical men in the fashionable world were striving - often successfully-to amass fortunes, spur the reader to read on. He then surveyed the literature. The Devonshire colic was first described in 1703 by Dr. William Musgrave, of Exeter. (This Dr. William was a man of parts, an indefatigable antiquarian, and a well-known figure in Exeter for 30 years.) The disease appeared to be similar to one described in Poitiers by Francis Citois in 1617, due to certain growths of wine. Next Baker pointed out that the colic was precisely the same disease as regards its symptoms as that brought on by all the saturnine preparations.

If, as Huxham had believed, it were due to the acid in the apples, why were not the inhabitants of Worcester, Gloucester, and Hereford subject to it ? The evidence of a physician of Worcester, Dr. Wall, was obtained on this point. Wall, of Worcester, was one of those erudite men who are always giving advice on many diverse subjects. Collectors of porcelain regard those pieces designed and decorated by him as prizes well worth the hunt. He was one of the founders of the Worcester Royal Infirmary. The evidence of such a man was incontrovertible; he wrote: "The counties of Hereford, Gloucester and Worcester are not subject to the colic ... or any other endemic illness unless it be the rheumatism. . . . There is no lead, which can give occasion to the colic, used in any part of the apparatus for grinding or pressing the apples, or fermenting the liquor," but he had heard of a farmer "who wanting casks, filled a large leaden cystern with new cyder." All who drank of it were affected as the lead workers usually were, and eleven were admitted to the infirmary at one time. 
The experience of Dr. Wall is contrasted with that at the Devon and Exeter Infirmary, where in less than five years 285 cases were admitted and 209 cured.

Dr. Andrew, of Exeter, is quoted as stating that, where the disease was obstinate, they endeavoured to get their patients to the hospital at Bath, " the Bath water, tho' not a specific, being esteemed by us as the most effectual remedy, both internally and externally used." Of 80 patients admitted to Bath hospital, 40 were said to have been cured and 36 greatly relieved. No doubt the sulphur in the spa water aided greatly in the elimination of the lead. It is salutary to think of the transfer of patients to so great a distance under voluntary arrangements so many years before the inception of the Welfare State.

Baker was not content with deductions from this evidence alone. He was able to show how the cider-presses in Devon, made of moorland granite, were held together by iron staples, into the holes of which was poured molten lead. The uneven cracks between the stones were treated in the same way. To complete the chain of evidence, it was necessary to prove that the cider itself contained lead, and he procured from a farm at Alphington in October, 1776 , a supply of fresh cider which he submitted to a Dr. Saunders, "an ingenious gentleman, who teaches chemistry," for help in its analysis. As a control, cider from Hereford was used. Evidence of lead was obtained in five experiments in the cider from Alphington but not in that from Hereford. As might be expected, Baker's work aroused a great deal of opposition in the county, and efforts were made to disprove it: prominent among these was the druggist Cockworthy, the founder of the Plymouth pottery.

Baker's classic was the first successful systematic inquiry into the cause and prevention of an epidemic disease.

\section{The Age of Cholera}

Like plague, cholera invaded Europe from the East, and this kingdom had ample warning of its approach. In 1830 it broke out in Russia, and the Government sent out two medical observers to watch its progress and report on the best methods of treatment. In 1831 was established a Board of Health, whose chief members were the leading Fellows of the Royal College of Physicians. The board got rapidly to work and Orders in Council soon appeared, together with "certain rules and regulations proposed by the board."

How did the local authorities respond to these orders? Thomas Shapter describes the uncertain, fluctuating state of feeling in Exeter, but shows that within four days of the receipt of the Order in Council a public meeting was held and a local board of health constituted, consisting of the mayor and magistrates, the Lord Bishop and one other member of the Chapter, six medical gentlemen, and the three medical officers of the poor. There seems to have been a subtle difference between the medical gentlemen and the medical officers, which is worth noting as an indication of the relative status of the various sections of the profession.

At subsequent meetings, arrangements were made for the notification by " all medical practitioners, and all other persons within the city" to members of the board. One thousand pounds was voted for "the covering in and making such drains as may be absolutely necessary for the protection of the health of the inhabitants as also for procuring water and for cleansing the streets." A handbill was circulated in which the need for cleanliness-public and personal-was stressed. It was accompanied by first-aid instructions for cholera. These included the application of local warmth by hot blankets, repeated friction, bags of hot salt or bran, the exhibition of stimulants such as hot brandy and water, sal volatile in hot water, essential oils such as peppermint, cloves, and cajeput, and, in very severe cases where medical aid was unobtainable, 20-40 drops of laudanum. At the instance of the bishop, an address from the clergy was widely circulated which concluded with these comforting words: "We pray God to prepare you for any trials or afflictions which he may be pleased to bring upon you: and to make this and every other visitation of his conducive to your happiness and salvation."

Exeter at that time was a city of 28,242 inhabitants, for the most part crowded within the walls. The streets were narrow and, except for the main thoroughfares, paved with rounded pebbles with a central gutter which was the only channel by which sewage and waste water was removed; and water was so scarce that it was seldom sufficient to wash it away. The main supply was from numerous wells, an ancient conduit, a few pumps, and the waterworks. These last had been improved, but were still quite insufficient for the needs of the people, and much of the water was obtained by dipping in the river in just the same way as is still the custom in the East. The water thus obtained was carried in buckets for use near the river and by small watercarts for those living further away. Night soil and sewage were collected by contractors, who were paid $£ 63$ per annum for the privilege, with the result that only when there was sufficient collected in one place did the contractors consider it worth their while to remove it. These were the conditions that the board of health set itself to correct. The whole city was surveyed. Orders to landiords instructing them to remove nuisances were issued by the mayor on threat of prosecution. Extra scavengers were employed, carts and horses purchased. To encourage cleanliness amongst the poor, special water tickets were distributed by the doctors, clergy, and others.

In preparation for the outbreak, the medical gentlemen took an active part in the organization of the medical arrangements. At general meetings of the profession they recommended that the town be divided into four districts with a medical officer in charge of each, and that in each section a station house be established, under the direction of a responsible person, from which blankets, warm-air baths, and other such appliances could be distributed, and where the following medicines could be held for the use of the medical attendants : opium, calomel, aether, ammonia, oils of peppermint and cinnamon, soda, mustard, turpentine, spirits of wine, and any other drugs which might be required-and brandy. Eight extra apothecaries were engaged by the corporation. The work of the profession was very heavy during the outbreak, and we learn that several of them broke down under the strain. When the epidemic was at its height a rota system was arranged, whereby two medical men did night duty at the Guildhall; for them the board of health engaged two carriages and employed a man to attend upon them and to make coffee. Nurses were also engaged, and these "very necessary persons" were paid at a rate of $2 \mathrm{~s}$. 6d. per day.

When the disease struck it rapidly increased, and after a fortnight over 100 cases had occurred, and of these 33 were fatal. Altogether, during the three months that it lasted there were 1,135 cases and 345 deaths.

Shapter gives a summary of treatment, from which we gather that nothing specific was considered effective. But Exeter had learnt its lesson; the water supply and sewage system were so improved that when in 1849 cholera again struck, although there were 2,366 deaths in the county, Exeter had only one or two cases.

Cholera came in epidemic waves, lasted a short time, and disappeared again; typhoid was nearly always present. In the case of typhoid William Budd was the man, North Tawton the place. While Budd was working in North Tawton in 1839 an epidemic of typhoid occurred, and he was quick to realize his opportunity. He says, "Having been born and brought up in the village, I was personally acquainted with every inhabitant of it; and being as a medical practitioner in almost exclusive possession of the field, nearly everyone who fell ill, not only in the village itself, but over a large area around it, came immediately under my care."

At that time it was held that typhoid, cholera, and many other infectious diseases were propagated through an atmospheric miasma. From his personal observations and from 
careful inquiry, Budd knew that fever had not been present in the village for at least 15 years-" There was nothing," he said, "to separate from the open air the offensive matters which collect around human habitations. Each cottage, or group of three or four cottages, had its common privy, to which simple excavation in the ground served as a cesspool." Also, nearly every farm labourer kept his pig to "furnish manure for the little plot of potatoes which fed man and pig alike. Thus, often, hard by the cottage door there was not only an open privy, but a dungheap also." Thus the atmospheric conditions considered necessary for the propagation of fever were present, and always had been. "Meanwhile privies, pigstyes and dungheaps continued, year after year, to exhale ill odours, without any specific effect on the public health."

In July the first case occurred; by November there had been more than 80 cases. It was by watching the spread of the disease within the families and neighbouring villages that Budd was able to demonstrate its contagious nature. When the disease was at its height three people left the village after they had been infected, and communicated it to others in their new neighbourhoods. Two were sawyers who had hired themselves out to a timber merchant in North Tawton for a few weeks, and had lodged in a court with a common privy. Both, when they sickened, returned to their homes in Morchard. One, a married man, died after passing the disease to his two children; his widow escaped. The other, a single man, infected a friend who visited him, and gave the disease to his brother and two of his children. The third person to leave North Tawton was a widow who went to visit her brother at Chaffcombe about seven miles away and started a series of cases: her sister-in-law, her brother, several farm labourers and apprentices, and other servants were affected. A servant-girl, in order to lessen the burden of sick nursing, went to her home in Loosebeare about four miles away and there started a small epidemic in the village. Budd points out that "while at Loosebeare a large proportion of the inhabitants were lying prostrate with fever, in not one of the 20 or 30 exactly similar places was there a single case." From Chaffcombe, again, one of the boys went home to his mother's cottage, half-way between Bow and North Tawton, and caused the illness of his mother and the death of his sister, and from there a further series of cases resulted.

Step by step Budd showed how the disease had been passed from one person to another. Soon after, he moved to Bristol, where he became an honorary and consulting physician to the Bristol Royal Infirmary. Whenever opportunity occurred, he collected further cases to illustrate his hypothesis. These he published in 1873 in a book, Typhoid Fever; its nature, mode of spreading and prevention.

\section{Conclusion}

What are the lessons to be learnt from these disjointed jottings? First, I would say, that history shows us that epidemic disease is always threatening, and when one appears to have been conquered or has spent its force others take its place, sometimes appearing insidiously, so that at first we hardly realize the changing pattern of disease in our midst-sometimes, with catastrophic force, breaking into our daily lives, as Asiatic cholera did in 1832 and influenza did in 1918. Even to-day we find fresh diseases coming amongst us unexpectedly. The polio epidemics which we have experienced since the war are an example. Epidemics of Bornholm disease which have caused considerable trouble in various parts of the country during the past year are another. What, I wonder, will our future historians say about the epidemics of this age ?

When it comes to the study of epidemiology, those situated in country districts, serving isolated communities, are in a far better position to help in unravelling the spread of disease. With an active chain of public health laboratories at the disposal of the country doctor, he can now make very real contributions to the advancement of medical science.

\section{BIBLIOGRAPHY}

Baker. Sir George, An Essay Concerning the Cause of the Endemial Colic of Nevonshire. J. Hughs, London. 1767.

Budd, Willam, Typhoid Fever. Longmans, Green and Co., London. 1873. Canter, J. R., and Wainwright, J., Reprint of the Barnstaple Records. 2 vols. Barnstaple. 1900.

Creighton, Charles, A History of Epidemics in Britain. 2 vols. University Press, Cambridge. 1891, 1894.

Hoskins. W. G., Devon. Collins, London. 1954.

uxham, John, Observations on the Air and Epidemical Diseases, made in Plymouth from the year 1728 to the end of the year 1737. J. Hinton. London. 1759.

Pickard. Ransome, The PoD

Times. Exeter. 1947.
resent Remedies Against the Plague. Shakespeare Association Facsimiles,

No. 7. London. 1933.

Nher. Thomas. The History of the Cholera in Exeter in 1832. Churchill,

London. 1849.

kin. H. R., The History of Totnes Priory and Medieval Town, 2 vols. 1914-17.

Plymouth. 1893 .

Tavistock Parish Records. Plymouth. 1887.

\section{CHILDREN'S VISION AND TELEVISION} BY

\section{A. H. GRIFFITH, M.B., B.S., D.P.H. Senior Medical Officer, City of Cardiff}

\section{General Effects of Television on Child Development}

The possible adverse or beneficial effects of television viewing on the physical, social, and mental development of children rarely form the subject of articles or discussions in medical journals, and only a few surveys have been carried out in order to determine these effects. This is surprising, as there are television sets in half the homes of the country, and during the last 10 years television viewing has developed from a curious pastime of a few Londoners into a regular nightly drawn-out vigil practised by a large mass of the population.

The existence of television in a home must necessarily affect the pattern of life of that family, probably only to a negligible degree but possibly to a considerable extent. It has been stated that the less-educated members of the community, those who have nothing in particular to do, and those in the lower socio-economic group take to television more readily and change their habits more radically than other sections of the community do.

The acquisition of a television set may accentuate the financial difficulties of some families, thereby adversely affecting the quality of meals and the standards of comfort provided; and outside the home it may restrict social, recreational, and other mentally or physically beneficial activities. On the other hand, the lure of the screen may induce parents to remain at home rather than visit public houses, clubs, etc., and encourage children to stay in instead of going to cinemas or wandering aimlessly in the streets. Does this mean that television encourages a more compact family life, or does it encourage each member to stare mutely at the screen instead of contributing to the intimate family chatter ? Where members of the family have no hobbies, do not read, and have no interesting conversation to offer, it relieves the boredom of home life.

A survey carried out in Coventry revealed that onefifth of the teenage children questioned admitted that television interfered appreciably with their homework. The programmes may stimulate thought, improve appreciation of the arts, extend knowledge of literature, and produce better understanding of social problems, but they may also encourage a child to depend on readymade entertainment, dampen initiative, discourage rational reasoning, and decrease his readiness to accept responsibilities. The youth club which the child may 